\title{
A Study of cardiac functions in type-2 diabetic patients
}

\author{
Panda $\mathbf{P}^{1}$, Mohapatra $\mathrm{D}^{2}$, Panda $\mathrm{SK}^{3}$, Mishra $\mathrm{T}^{4}$, Priyadarsini $\mathrm{N}^{5}$, Behera $\mathrm{M}^{6}$ \\ ${ }^{1}$ Dr Priyambada Panda, PhD Student com Tutor, Department of Physiology, ${ }^{2}$ Dr Dipti Mohapatra, Associate Professor, \\ Department of Physiology, ${ }^{3}$ Dr Sitansu K. Panda, Professor, Department of Anatomy, ${ }^{4}$ Dr Tapaswini Mishra, Assistant \\ Professor, Department of Physiology, ${ }^{5} \mathrm{Dr}$ Nibedita Priyadarsini, Associate Professor, Department of Physiology, \\ ${ }^{6}$ Dr Manasi Behera, Associate Professor, Department of Physiology. All are affiliated with IMS \& SUM Hospital, \\ Bhubaneswar, Odishsa, India.
}

Address for Correspondence: Dr Priyambada Panda, Email: purabipriyambada@gmail.com

\begin{abstract}
Introduction: The cardiomyopathy in diabetes mellitus (DM) is the disorders in cardiac muscle due to prolonged exposure of vascular tissues to hyperglycemia in DM; and is termed as diabetic cardiomyopathy (DC). The early preclinical features of DC are the left ventricular diastolic dysfunction (LVDD), preceding the systolic dysfunction and being able to evolve to symptomatic heart failure. Methods: A cross-sectional study was done including 50 DM-2 patients without any feature of cardiovascular involvement and blood pressure less than 130/80 mmHg. Doppler echocardiography was done to evaluate LVDD. Results: In this study results showed diastolic dysfunction was more common among female than male. The prevalence of diastolic dysfunction is more in cases of longer duration of DM. Conclusion: Our study supports other studies that myocardial damage in DM-2 affects diastolic dysfunction before systolic dysfunction. As Doppler echocardiography is a simple non-invasive procedure to assess cardiac function, so in diabetes it should be done routinely in DM for early diagnosis and prevention of further complications.
\end{abstract}

Keywords: Diabetic cardiomyopathy, Diabetes mellitus, Doppler echocardiography, Left ventricle.

\section{Introduction}

$\mathrm{DM}$ is a chronic, progressive metabolic disorder that can affect children, young and adults of any ages. DM generally results from defects in insulin secretion, action or both and clinically featured by hyperglycemia, glycosuria, polydipsia and polyurea. DM is looming large as an epidemic in developed and developing countries; causing considerable human suffering both on health and wealth. In the world, India is becoming the capital for diabetes, as per the recorded cases estimated in 2012 is 50.8 million and estimated to increase the number to 70 millions by $2025[1,2]$.

Despite of enormous availabilities and research done to control its growth rate, the number of cases are ever increasing [3, 4]. The prime causes of disability, morbidity and premature deaths in DM is due to its complications, both macrovascular and microvascular [4]. The disorders in heart muscle due to or presumably

Manuscript received $2^{\text {nd }}$ June 2016

Reviewed: $13^{\text {th }}$ June 2016

Author Corrected: $24^{\text {th }}$ June 2016

Accepted for Publication $5^{\text {th }}$ July 2016 due to prolonged exposure of vascular tissues to hyperglycemia in DM is termed as diabetic cardiomyopathy [5]; which was first proposed by Ruber et al, 1972. This is also supported by Framingham study, 1974 [6, 1]. Subsequently, in animal and human research studies, it have been demonstrated that, diabetic persons are more prone to both systolic and diastolic abnormalities [1]. According to current American Heart Association (AHA) guidelines, Heart Failure (HF) is a complex clinical syndrome resulting from defective ventricular filling or blood ejection (structural or functional), producing dyspnoea, fatigue, oedema, rales, etc [7]. In diabetes mellitus, ventricular failure is a common and serious comorbidity [8].

The relationship between DC and indices of metabolic control in DM is still a matter of debate. Some studies have found correlation between glycemic control and left ventricular diastolic dysfunction (LVDD), while other studies have found no such correlation. The aim of this study was to determine the prevalence of diabetic 
cardiomyopathy (DC) among the DM patients attending IMS \& SUM Endocrinology Dept, BBSR. This study aims to determine the prevalence of DC among males and females and occurrence of DC in relation with their duration of diabetes.

\section{Materials and Methods}

A total of 100 subjects attending outpatient department (OPD) and indoor patient department (IPD) of Endocrinology, IMS \& SUM hospital, Bhubaneswar were recruited for the study. These consist of 50 known diabetic patients who clinically had no symptoms of cardiovascular involvement and blood pressure < $130 / 80 \mathrm{mmHg}$ were included in Group 1. 50 age and sex matched healthy individuals who were not diabetic and had no evidence of cardiovascular disease by history analysis; physical examination and echocardiography were included in Group 2. All patients with type 2 diabetes with other cardiac diseases like valvular heart disease, ischemic and hypertensive heart disease, congestive heart failure, cardiomyopathy were excluded from study. The approval of study was obtained from the Institutional Ethical Committee. Arrangement was made with the clinicians whereby subjects who satisfy the inclusion criteria were selected.

Their history analysis was done which includes the duration of diabetes in a questionnaire form. Then their physical examination was done including height, weight and blood pressure. Their serum analysis was done to determine FBS (fasting blood Sugar) and PPBS (post prandial blood sugar) [measured by using enzymatic method of Trinder]. Their GHbA1c (glycosylated hemoglobin) was measured using micro column method of Trivelli et al. The echocardiographic parameters were recorded with the ultrasound system (GE VOLUSON series S6 model); in Cardiology department of the institution. M mode echo: left ventricular internal dimensions (LVIDd \& LVIDs), interventricular septal thickness (IVSs \& IVSd); left ventricular posterior wall thickness (LVPWs \& LVPWd); Ejection fraction (EF \%). Doppler echo studies: peak early mitral filling velocity $(\mathrm{E})$, peak mitral atrial velocity during last diastole (A), their ratio (E/A).

Criteria for left ventricular hypertrophy were based on interventricular septum and left ventricular posterior wall values $>13 \mathrm{~mm}$. Systolic dysfunction was indicated by Ejection fraction $<50 \%$. Echocardiographic Diastolic Dysfunction Criteria for enrollment in the study was based on Mitral E/A ratio $<1$ or $>2$.

All the data collected was analyzed statistically using the $\mathrm{Z}$ test. Statistical significance was estimated by calculating the ' $\mathrm{p}$ ' value, with significance assigned at $\mathrm{p}$ $<0.05$. $\mathrm{P}$ values $<0.01$ were considered to be highly significant.

\section{Results}

Basic characteristics of study population are given in Table-1. Data were presented in mean \pm standard deviation. ( $\mathrm{M} \pm$ $\mathrm{SD})$.

Table-1: Basic characteristics of the study population.

\begin{tabular}{|c|c|c|c|}
\hline Parameters & Study group (Gp-1) M \pm SD & $\begin{array}{c}\text { Controls (Gp-2) } \\
\text { M } \pm \text { SD }\end{array}$ & p-value \\
\hline Age $(\mathrm{yrs})$ & $42.48 \pm 14.84$ & $41.43 \pm 16.34$ & Ns \\
\hline BMI $\left(\mathrm{kg} / \mathrm{m}^{2}\right)$ & $24.26 \pm 3.11$ & $21.57 \pm 2.79$ & $*$ \\
\hline SBP $(\mathrm{mmHg})$ & $120 \pm 4$ & $118 \pm 8$ & Ns \\
\hline DBP $(\mathrm{mmHg})$ & $80 \pm 6$ & $78 \pm 4$ & Ns \\
\hline FBS $(\mathrm{mg} / \mathrm{dl})$ & $179.7 \pm 58.19$ & $88.15 \pm 17.23$ & $* *$ \\
\hline PPBS $(\mathrm{mg} / \mathrm{dl})$ & $224.6 \pm 87.84$ & $109.5 \pm 21.13$ & $* *$ \\
\hline HbA1c $(\%)$ & $8.9 \pm 1.3$ & $4.5 \pm 1.5$ & $* *$ \\
\hline
\end{tabular}

BMI: body mass index, SBP: systolic blood pressure, DBP: diastolic BP, FBS: fasting blood sugar, PPBS: post prandial blood sugar, HbA1c: glycosylated hemoglobin, Ns: not significant, *: significant.

The average age of diabetic patients was $42.78 \pm 14.84 \mathrm{yrs}$. The mean age for control was $37.43 \pm 16.34 \mathrm{yrs}$. There is no significant difference among both groups; which shows our both study population are age-matched.

$\mathrm{M}$ mode parameters in Diabetics and control are given in table-2. 
Table-2: M-mode parameters in the study population.

\begin{tabular}{|c|c|c|c|}
\hline Parameters & $\begin{array}{c}\text { Study group(Gp-1) M } \pm \\
\text { SD }\end{array}$ & $\begin{array}{c}\text { Controls (Gp-2) } \\
\text { M } \pm \text { SD }\end{array}$ & p-value \\
\hline LVIDd (cms) & $4.33 \pm 0.57$ & $4.27 \pm 0.33$ & Ns \\
\hline LVIDs (cms) & $2.14 \pm 0.13$ & $2.02 \pm 0.35$ & Ns \\
\hline LVPWd (cms) & $1.05 \pm 0.23$ & $1.04 \pm 0.17$ & Ns \\
\hline IVSd (cms) & $1.17 \pm 0.34$ & $1.13 \pm 0.16$ & Ns \\
\hline IVSs (cms) & $1.23 \pm 0.35$ & $1.15 \pm 0.11$ & Ns \\
\hline EF (\%) & $62.7 \pm 4.6$ & $64.5 \pm 5.9$ & $185 \pm 15.56$ \\
\hline
\end{tabular}

$\dagger$ LVIDd \& LVIDs: left ventricular internal dimensions both at end diastole and systole, LVPWd: LV posterior wall thickness in diastole, IVSd \& IVSs: interventricular septal thickness in diastole and systole, EF: ejection fraction, LV Mass: left ventricular mass, Ns: not significant, *: significant.

Interventricular septum thickness, left ventricular dimensions i.e. IVS and left ventricular posterior wall thickness were greater in diabetic group $(\mathrm{p}<0.01)$. All subjects showed normal systolic function. Out of a total of 50 diabetics, $32(64 \%)$ patients had diastolic dysfunction.

2-D Echo and Doppler parameters in Diabetics and controls are given in table-3.

Table-3: 2-D Echo and Doppler parameters in the study population.

\begin{tabular}{|c|c|c|c|}
\hline Parameters & $\begin{array}{c}\text { Study group(Gp-1) M } \pm \\
\text { SD }\end{array}$ & $\begin{array}{c}\text { Controls (Gp-2) } \\
\text { M } \pm \text { SD }\end{array}$ & p-value \\
\hline MVE (m/sec) & $0.53 \pm 0.14$ & $0.57 \pm 0.12$ & Ns \\
\hline MVA (m/sec) & $0.63 \pm 0.16$ & $0.44 \pm 0.05$ & $*$ \\
\hline MV E/A & $0.9 \pm 0.25$ & $1.34 \pm 0.3$ & $*$ \\
\hline
\end{tabular}

† MVE: peak early mitral filling velocity (E), MVA: peak mitral atrial velocity during last diastole (A), MV E/A: their ratio(E/A), Ns: not significant, *: significant.

The data show a higher atrial peak filling velocity $\left.(\mathrm{A}){ }^{*}\right]$ in diabetics. Consequently, a reduced E/A ratio $[\mathrm{P}<0.05]$. Out of a total of 50 diabetics, $32(64 \%)$ patients had diastolic dysfunction. Duration of DM versus LVDD prevalence are given in table- 4 .

Table-4: prevalence in \% of Left ventricular diastolic dysfunction among diabetic patients based according to their diagnosed duration of DM.

\begin{tabular}{|c|c|c|c|}
\hline $\begin{array}{c}\text { Duration of disease } \\
\text { (years) }\end{array}$ & Numbers screened & $\begin{array}{c}\text { Diseased number } \\
\text { (DM + LVDD) }\end{array}$ & Prevalence (\%) \\
\hline $0-1$ & 15 & 4 & 26.66 \\
\hline $1-2$ & 12 & 8 & 66.66 \\
\hline $2-4$ & 13 & 10 & 76.92 \\
\hline $4-10$ & 10 & 10 & $\mathbf{6 4}$ \\
\hline Total & $\mathbf{5 0}$ & $\mathbf{3 2}$ & \\
\hline
\end{tabular}

Prevalence of LVDD in Diabetic males \& females is given in table-5. This study shows, there was a high prevalence of LVDD among female (73.33\%) than males (57.14\%). 
Table-5: Gender distribution among the study group in percentage (\%).

\begin{tabular}{|c|c|c|c|c|}
\hline Gender & DM + LVDD & \% & DM - LVDD & \% \\
\hline Male (35) & 20 & 57.14 & 15 & 42.85 \\
\hline Female (15) & 11 & 73.33 & 4 & 26.66 \\
\hline
\end{tabular}

\section{Discussion}

There is an important diagnostic, prognostic and therapeutic value of early detection of LVDD. Diabetic patients are more prone to have heart failure, even with normal left ventricular systolic function. LVDD may represent as potential marker of DC in DM patients $[15,16,17]$.

The V-HeFT Study showed mitral E/A ratio have better prognostic value than left ventricular systolic indices [18]. Different studies have also shown that there is a beneficial effect of exercise on diastolic function [19].

Our study shows that the diastolic dysfunction is common in type 2 diabetes mellitus patients. Increase in collagen deposition and myocyte fibrosis can develop the diastolic dysfunction in diabetic models, which was shown by different histopathological studies [20]. High concentration of glucose causes formation of Advanced Glycation End-products (AGEs) that cause change in collagen structure [21].

Diabetes also has adverse effects on myocardium, causing glucotoxicity, lipotoxicity, mitochondrial dysfunction, impaired calcium homeostasis, increased oxidative stress [22, 23]. These alteration leads to necrosis of cardiomyocyte and apoptosis which is associated with myocardial fibrosis and subsequent myocardial dysfunction, called diabetic cardiomyopathy $[20,24]$.

The present study provides evidence that LV function is impaired im DM2 patients. The prevalence rate of LVDD was $64 \%$ in this study, while our age and sex matched controls had no LVDD, which shows a good diabetic relation among them. The percentage of diastolic dysfunction with DM in our study is compared with other studies (table-6). So this study is also in support to other studies. [6, 9-13].

Table-6: Comparison of \% distribution of diastolic dysfunction in diabetic patients with other studies.

\begin{tabular}{|c|c|}
\hline Studies & Percentage (\%) \\
\hline Nikhil M. et al[9] & 66 \\
\hline Patil VC et al[10] & 54.33 \\
\hline Poulsen et al [25] & 40 \\
\hline Eichelberger et al[11] & 62 \\
\hline Kurshid et al [12] & 60 \\
\hline Patil MB et al[6] & 64 \\
\hline Poirier et al[13] & 60 \\
\hline Annonu et al [26] & 60 \\
\hline Present study & 64 \\
\hline
\end{tabular}

This study shows the lowest prevalence of LVDD in DM of short duration as compared to more prevalence in DM of longer duration (26.66\% in DM $\leq 1$ year duration Vs $100 \%$ in DM of 4-10 years duration).

This implies the longer duration of disease probably give more time for development of LVDD. This also supports other studies [27]. this study find no LV systolic dysfunction in any subject of study group, which is similar with many other studies $[5,13]$. 
Table-7: Comparisons of E/A ratio in patients with diastolic dysfunction.

\begin{tabular}{|c|c|}
\hline Studies & $\begin{array}{c}\text { Diabetics with diastolic dysfunction } \\
\text { E/A }(\mathbf{M} \pm \mathbf{S D})\end{array}$ \\
\hline Nikhil M et al[9] & $0.90 \pm 0.27$ \\
\hline Paul Poirier et al[13] & $0.79 \pm 0.07$ \\
\hline Schanwell et al[14] & $0.80 \pm 0.15$ \\
\hline Patil MB et al[6] & $0.72 \pm 0.24$ \\
\hline Present study & $0.90 \pm 0.25$ \\
\hline
\end{tabular}

It was observed that E/A ratio was significantly abnormal $(<1)[\mathrm{p}<0.05]$ in diabetics as compared to the value in normal controls (>1). Comparison of E/A ra

So myocardial damage in diabetic patients causes diastolic dysfunction in $64 \%$ patients before systolic dysfunction, tio in patients with diastolic dysfunction is given in table-7. In Nikhil $\mathrm{M}$ et al study there was no significant decrease in the ejection fraction in diabetics [9]. The study done by Patil MB et al shows there was a higher decrease in E/A ratio( $0.72 \pm$ 0.24). [6]. Several other studies also show a decrease value E/A [13, 14]. Diamant et al study found the ratio of peak early mitral filling velocity and peak mitral atrial velocity during last diastole (E/A) of diastolic function decreased significantly in well controlled, recently diagnosed, uncomplicated diabetic patients in comparison to controls [28]. Our finding is also similar to these findings.

\section{Conclusion}

which is suggestive of pre-clinical diabetic cardiomyopathy. Doppler Echo is simple, non-invasive and reproducible technique, which can identifies asymptomatic left ventricular dysfunction in diabetic patients in large percentage before abnormalities are detected by clinical examination or with ECG. So it is suggested that all patients of diabetes should be routinely and repeatedly subjected to 2-D color Doppler Echocardiographic assessment of cardiac functions in the long-term management of this metabolic disease.

Acknowledgement:- The author thanks Dr Kiran Dukhu, Professor \& HOD, Department of Physiology; Dr Sudhanshu S. Mishra, Professor \& HOD, Department of Pharmacology; Dr Suresh K. Behera, Department of Cardiology; Dr Abhay K. Sahu, Department of Endocrinology, IMS \& SUM Hospital, Bhubaneswar, for their kind support.

Funding: Nil, Conflict of interest: None initiated, Permission from IRB: Yes

\section{References}

1. Hameedullah, Faheem M, Khan SB, Hafizullah M. Prevalence of asymptomatic left ventricular diastolic dysfunction in normotensive type 2 diabetic patients. J Postgrad Med Inst [Internet]. 2010 ;24(3):188-92.

2. Bhatt JK, Thomas S, Nanjan MJ. Effect of Oral Supplementation of Vitamin C on Glycemic Control and Lipid Profile in Patients With Type 2 Diabetes
Mellitus. Int J Pharm Sci. 2012 Jan;4(2):524-27.

3. Verma S, Sagar N, Vats P, Shukla K N, Abbas M, Benerje M. Antioxidant enzyme levels as markers for type 2 diabetes mellitus. Int $\mathrm{J}$ Bioassays. 2013;02(04):685-90.

4. Kuchake VG, Upasani CD. Evaluation of Protective Effect of Antioxidant Vitamins in Patients with Diabetic Nephropathy. Asian Pharm Clin Res. 2011; 4(4): 52-54.

5. Khalil SI, Kamal A, Hashim F et al. Study of Left Ventricular Diastolic Function in Patients with Diabetes Mellitus.Sudan J Med Sci. 2007; 2(June):85-90.

6. Patil MB, Burji NP. Ehocardiographic evaluation of diastolic dysfunction in asymptomatic type 2 diabetes mellitus. J Assoc Phsicians India.2012 May; 60 (5): 23-6.

7. Fauci AS, Braunwald E, Kasper DL, Hauser S, Longo DL, Jameson JL, et al., editors. Harrison's principles of internal medicine. $19^{\text {th }}$ ed. United state of America: cenveo publisher services; 2015.

8. David SHBell. Heart failure: The frequent, forgotten, and often fatal complication of diabetes. Diabetes Care. 2003 Aug;26(8):2433-41. Doi: http://dx.doi.org/ 10. 2337/diacare.26.8.2433. 
9. Dikshit NM, Wadia PZ, Shukla DK. Diastolic dysfunction in Diabetes Mellitus. Natl J Med Res. 2013; 3(3): 249-252.

10. Patil VC, Patil HV, Shah KB, Vasani JD, Shetty P. Diastolic dysfunction in asymptomatic type 2 diabetes mellitus with normal systolic function. J Cardiovasc Dis Res.2011;2(4):213-222.Doi:10.4103/0975-3583.89805.

11. Albanna II, Eichelberger SM, Khoury PR, Witt SA, Standiford DA, Dolan LM, Daniels SR KT. Diastolic dysfunction in young patients with insulin-dependent diabetes mellitus as determined by automated border detection. J Am Soc Echocardiogr. 1998;11(4):349-55. Doi: http://dx.doi.org/10.1016/S0894-7317(98)70102-6.

12. Khan KA, Jalal S, Baba RM, Jan V, Rather H, Alai M, Lone NA, Malik AR. Prevalence of diastolic dysfunction in normotensive asymptomatic patients with well controlled type 2 diabetes mellitus. JOURNAL of CHINESE CLINICAL MEDICINE. 2006 Sep; 1(4):193-200.

13. Poirier $\mathrm{P}$, Bogaty $\mathrm{P}$, Garneau $\mathrm{C}$, Marois L, Dusmenil J. Diastolic Dysfunction in Normotensive men with well-controlled type 2 diabetes. Diabetes Care. 2001; 24 (1) :5-10. Doi: http : //dx. doi. org/10. 2337/diacare. 24.1.5

14. Schannwell CM, Schoebel FC, Heggen S, et al. Early decrease in diastolic function in young type I diabetic patients as an initial manifestation of diabetic cardiomyopathy. Z Kardiol. 1999;88(5):338-46. Doi: http://dx.doi.org/ 10.1007/s003920050295.

15. Raev DC. Which left ventricular function is impaired earlier in the evolution of Diabetic cardiomyopathy? An Echocardiographic study of young type 1 diabetic patients. Diabetes Care. 1994 Jul;17 (7): 633-39. PMID: http://www.ncbi.nlm.nih. gov/ pubmed/ 7924771.

16. Zarich SW, Arbuckle BE, Cohen LR, et al. Diastolic abnormalities in young asymptomatic diabetic patients assessed by Pulsed Doppler Echo. J Am Coll Cardiology. 1988 Jul;12(1):114-20. PMID: http://www. ncbi.nlm.nih.gov/pubmed/3379197

17. Riggs TW, Transue D. Doppler Echocardiographic evaluation of left ventricular diastolic dysfunction in adolescents with Diabetes Mellitus. Am J Cardiol. 1990 Apr;65(13):899-902. PMID: http://www.ncbi.nlm.nih. gov/pubmed/2321540.

18. Cohn JN, Johnson G. Heart failure with normal Ejection Fraction: the V-HeFT study. Circulation. 1990 Feb;81(2 suppl): III 48-53. PMID: http://www.ncbi. nlm.nih.gov/pubmed/2321540.

19. Forman DE, Manning WJ, Hauser R, et al. Enhanced left ventricular diastolic filling associated with long-term endurance training. J Gerontol. 1992 Mar;47(2):M56-8. PMID: http://www.ncbi.nlm.nih. gov/pubmed/1538067.

20. Zahiti BF, Gorani DR, Gashi FB, et al. Left Ventricular Diastolic Dysfunction in Asymptomatic Type 2 Diabetic Patients: Detection and Evaluation by Tissue Doppler Imaging. Acta Inform Med. 2013 Jun; 21 (2): 120 - 23. Doi: 10. 5455 / aim . 2013 . 21. 120122.

21. Ren J, Davidoff AJ. Diabetes rapidly induces contractile dysfunctions in isolated ventricular myocites. Am j Physiol. 1997 Jan;272(1): H 148-58. URL: http://jpheart.physiology. org/content/ 272/1/ H148.abstract

22. Boudina S, Abel ED. Diabetic cardiomyopathy revisited. Circulation. 2007 Jun;115(25): 3213-23. Doi:10.1161/CIRCULATIONAHA.106.679597.

23. Asghar O, AI Sunni A, Khavandi K, et al. Diabetic cardiomyopathy. Clin Sci (lond).2009; 116(10): 741-60. Doi:10.1042/CS20080500.

24. Frustaci A, Kajstura J, Chimenti C, et al. Myocardial cell death in human diabetes. Circ Res.2000; 87(12): 1123-32. Doi: 10.1161/01. RES. 87.12.1123.

25. Poulsen MK, Henriksen JE, Dahl J, et al. Left Ventricular Diastolic Function in Type @ Diabetes Mellitus: Prevalence and Association with Myocardial and Vascular Disease. 2010 Jan;3(1):24-31. Doi:10.1161/CIRCIMAGING.109.855510. Epub 2009 Oct 21.

26. Annonu AK, Fattah AA, Mokhtar MS, et al. Left ventricular systolic and diastolic functional abnormalities in asymptomatic patients with noninsulin-dependent diabetes mellitus. J.Am.Soc. Echocardiogr. 2001 Sep; 14(9):885-91. Doi: 10.1067/ mje.2001.112892. 
27. Illan F, Valdes-Chavarri, Tebar J, et al. Anatomical and functional cardiac abnormalities in type $1 \mathrm{DM}$. Clin Invest. 1992 May; 70(5):403-10. Doi:10.1007/ BF 00235521.

28. Diamant M, Lamb HJ, Groeneveld $\mathrm{Y}$, et al.
Diastolic dysfunction is associated with altered myocardial metabolism in asymptomatic, normotensive patients with well-controlled type 2 diabetes mellitus. J Am Coll Cardiol. 2003;42:328-35. PMID: http://www. ncbi. nlm.nih.gov/pubmed/12875772.

\section{How to cite this article?}

Panda P, Mohapatra D, Panda SK, Mishra T, Priyadarsini N, Behera M. A Study of cardiac functions in type-2 diabetic patients. Int J Med Res Rev 2016;4 (7):1221-1227.doi:10.17511/ijmrr.2016.i07.25. 